\title{
Proposal of Measures for Increasing the Safety Level of Inland Navigation
}

\author{
Pero Vidan, Andrzej Grzadzielaa, Rino Bošnjak
}

Navigation along inland waterways was in history used only for the transportation of bulk cargo. However, in the last two centuries inland waterways have been used for transporting containers, general and liquid cargo. The density of navigation in the world waterways is considerable, especially because it is more profitable, when compared to other modes of transport. The increase of the density of navigation along inland waterways has also caused the threats of various undesired occurrences like collisions, stranding, pollution etc. Their decrease may be realised through the implementation of various measures relating to the safety of navigation along inland waterways.

In this paper the authors will present new measures aimed at the increase of the traffic volume. It is expected that the implementation of new measures will enable optimal planning of navigation and better awareness of potential threats in the waterways.

\section{KEY WORDS}

$\sim$ Inland waterways

$\sim$ Security

$\sim$ Treats

$\sim$ Protection

$\sim$ Safety
University of Split, Faculty of Maritime Studies, Zrinsko-Frankopanska 38, 21000 Split, Croatia

e-mail: pvidan@pfst.hr, rbosnjak@pfst.hr

a. Faculty of Mechanical \& Electrical Engineering, Gdynia, Poland

e-mail: a.grzadziela@amw.gdynia.pl

\section{SAFETY OF NAVIGATION AND INLAND WATERWAYS}

Safety of navigation assumes a set of conditions and requirements to be fulfilled by inland waterways, ports, navigation, ships and other vessels, the crew and supervision of implementation of navigational safety regulations. Inland waterways refer to the belt of inland waters of particular depths and widths along which navigation is performed. It can be presented by a general model of route between destinations $A$ and $B$ (Figure 1).

\section{PROPOSAL OF NEW MEASURES}

During the navigation along inland waterways various decisions are made. Part of the decisions is based on the information from the environment. Among other subjects, they refer to:

- Limited waterway along the river course,

- Hydrographic characteristics,

- Meteorological characteristics,

- Quantity of traffic in a limited area,

- Limited possibility of maneuvering,

- Branching, vicinity of towns and industrial plants, and

- Human error.

Inland navigation is specific also because of the limitation of the waterway along the river course, coastline of rivers, lakes and channels, river widths, number of meanders and radius of meanders, shallow water, water level, dams and locks, and other navigation obstacles, like cables, bridges etc. Such navigation requires frequent maneuvering and consequently additional attention of the navigator. It is therefore necessary to propose a system of measures for defining limitations of a waterway calculating the coefficients of: 


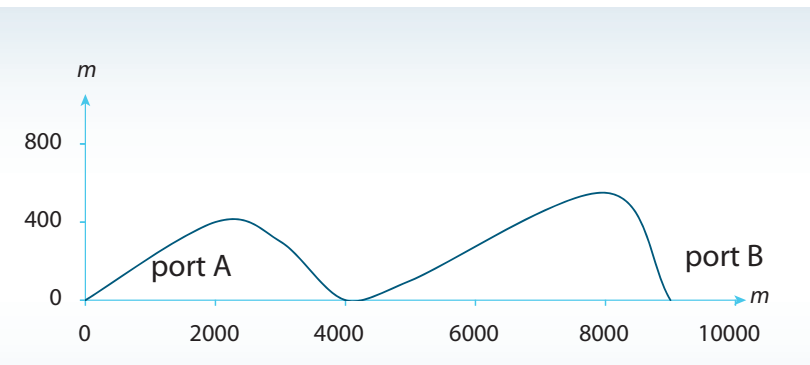

Figure 1. General model of inland waterway.

- Width of an inland waterway $\left(K_{w}\right)$,

- Indentedness of an inland waterway $\left(K_{i}\right)$, and

- Complexity of an inland waterway $\left(K_{c}\right)$.

The coefficient of width is the ratio between the full length of the waterway from the port $A$ to the port $B(I)$ and the width of the waterway $(w)$ :

$K_{w}=\frac{l}{w}$

The coefficient of indentedness of an inland waterway $\left(K_{i}\right)$ is the ratio between the full length of the river coastline $\left(I_{c l}\right)$ and the full length of the inland waterway $(I)$ :

$K_{i}=\frac{l_{c l}}{l}$

The coefficient of complexity of an inland waterway $\left(K_{S_{n}}\right)$ is the ratio between the total number of navigation threats ( $\sum_{0} 0$ ) and the length of the inland waterway $(I)$. Navigation thréats are threats like dangerous depths, shallow waters, locks, bridges, cables etc.

$K_{S}=\frac{\sum_{i=1}^{n} o_{i}}{I}$

Navigation along inland waterways is considered dangerous also because of unfavourable hydrographic characteristics of a waterway, especially when the water level and water currents reach extreme values. Water level and water currents may cause difficulties when manoeuvring the ship and cause complications in case of pollution, passing by other ships, drifts in rivers bends, entering channels, undesired increase or decrease of speed, dangerous objects brought by current, etc. When estimating the safety of sailing along a particular inland waterway it is proposed to use a coefficient of meander state of the river $\left(K_{w}\right)(4)$. It is the ratio between the sum of river bends $\left(\sum_{i=1}^{n} w\right)$ and the full length of the waterway and it provides information on the meander state of the river course.
$K_{w}=\frac{\sum_{i=1}^{n} w_{i}}{l}$

As in maritime navigation, meteorological properties may be a threat for ships in inland navigation in terms of safe manoeuvring of the ship. The ice may cause damage to the hull. The fog and reduced visibility jeopardise a safe manoeuvring of the ship in narrow passages and along the areas of higher traffic intensity. The wind may cause the drift of the ship in risky areas such as entrances to estuaries and channels, or it may lower the water level, as, for instance, in La Plata- Buenos Aires (Port of Buenos Aires, 2008).

From the aspect of meteorological influences, safe passage may be expressed by a coefficient of safe passage $\left(K_{\text {sap }}\right)$. It equals the ratio between the total number of navigable days of safe passage $\left(\sum_{i=1}^{n} d_{n}\right)$ and the number of days in a year:

$K_{\text {sap }}=\frac{\sum_{i=1}^{n} d_{i}}{365}$

Visibility coefficient $\left(K_{v s b}\right)$ is the ratio between the total number of days with reduced visibility $\left(\sum_{i=1}^{n} d_{n s b}\right)$ and the number of days in a year:

$K_{v s b}=\frac{\sum_{i=1}^{n} d_{r v s b_{i}}}{365}$

It is considered that the intensity of traffic in limited area of inland waterways is relatively high. In inland waterways, it is often navigated in the vicinity of locks, dams, industrial areas, narrow channels etc. Due to high traffic intensity in a relatively small area there is a higher probability of collision with other ships. Therefore, traffic density $\left(G_{p}\right)$ of a waterway can be measured. It equals the ratio between the total number of ships $\left(V_{b}\right)$ and the length of the waterway $(I)$ :

$G_{p}=\frac{\sum_{i=1}^{n} V_{b_{i}}}{l}$

In inland navigation there are relatively stronger water currents than in maritime navigation. Because of the nature of a waterway, ship maneuverings are more frequent and the distances from land and navigating objects are smaller in comparison to maritime coastal navigation.

Besides navigational hazards such as shallow waters, junctions of waterways and the like, inland waterways are intersected by road and railway bridges. They are additional threat to the safety of navigation. Rivers connect towns with the sea and have numerous tributaries for irrigation of agricultural areas, operation of industrial plants etc. Ports in such areas are of smaller capacity than marine ports, but they have a significant trend of traffic increase (Jolić, 2006). 
It is proposed to use measures for estimating potential human, material and other hazards (Kasum et al., 2006). In this way the density of various infrastructures in inland waterways can be measured, for instance:

- Density of inhabited places along the waterway $G_{n m}$,

- Population density along the waterway $G_{n a}$, and

- Density of potentially jeopardized objects along the waterway $G_{n o}$.

It is considered that the density of inhabited places along the waterway $\left(G_{n m}\right)$ equals the ratio between the total number of inhabited places along the waterway $\left(N_{m}\right)$ and the length of the waterway ( $/$ ) (Kasum et al., 2010; Vidan et al., 2009; Vidan et al., 2012):

$G_{n m}=\frac{\sum_{i=1}^{n} N m_{i}}{l}$

Population density along the waterway $\left(G_{n a}\right)$ is the ratio between the number of inhabitants there $(S)$ and the length of the waterway ( I ) (Kasum, et al, 2010; Vidan, et al 2012):

$G_{n a}=\frac{\sum_{i=1}^{n} S_{i}}{l}$

The density of potentially jeopardized objects along the waterway $\left(G_{n o}\right)$ is considered to equal the ratio between the number of jeopardized objects $(O)$ and the length of the waterway ( I ) (Kasum et al., 2010; Vidan et al., 2012):

$G_{n o}=\frac{\sum_{i=1}^{n} O_{i}}{I}$

Human negligence is a crucial factor in the situation of crisis. It can refer to accidental pollution of water, erroneously operating dams and lock, wrong estimates when maneuvering and the like. The coefficient of hazard due to human error can be expressed as a ratio between the number of accidents caused by human error $\left(\sum_{i=1}^{n} n_{h m}\right)$ and the length of the inland waterway $(I)$ (Inland Navigation Europe, 2007; Vidan et al., 2012):

$K_{h m}=\frac{\sum_{i=1}^{n} n h m_{i}}{l}$

In order to increase safety factors in inland waterways, the results presented in the proposed measures might be included in the information content of river maps and navigational publications. For example, the proposed measure of the coefficient of hazard due to human error could be presented as:

- Red mark

- Yellow mark $\triangle$, and

- Blue mark

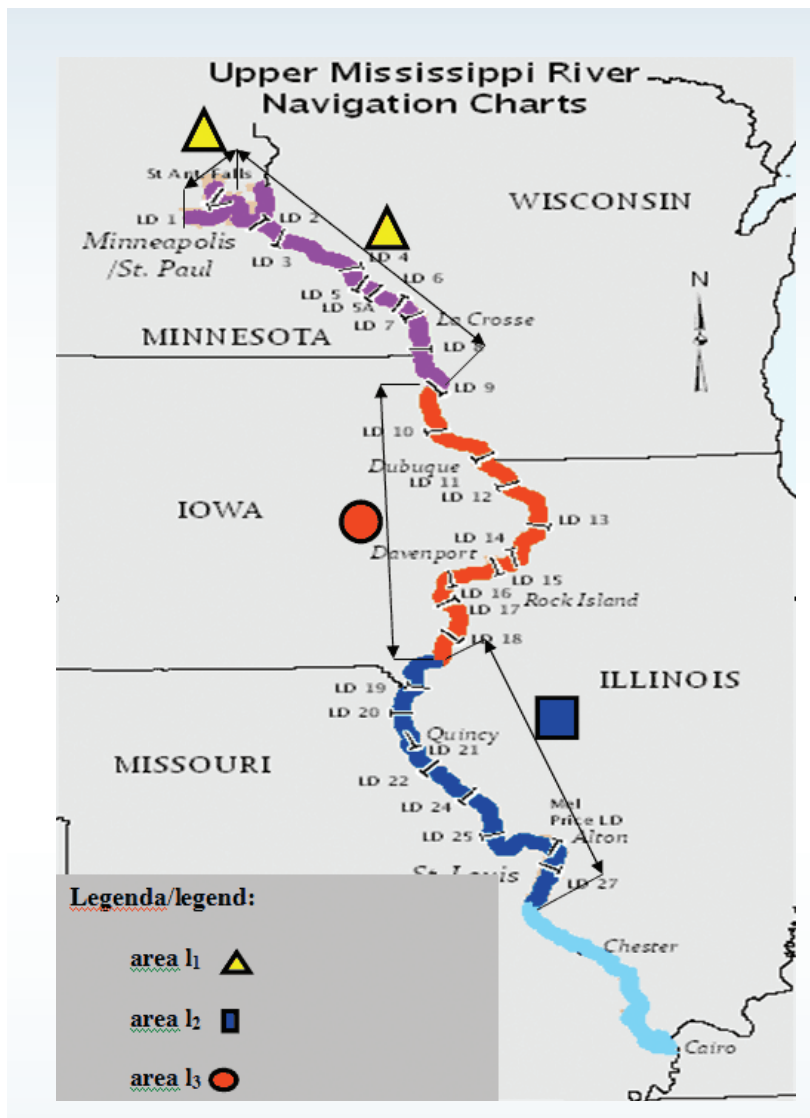

Figure 2. Example of areas with different values of the estimated coefficients of human errors in navigational area of the upper Mississippi river.

Source: http://www2.mvr.usace.army.mil/NIC2/mrcharts.cfm

The red mark indicates the area with frequent accidents caused by human error.

The yellow mark indicates the area with infrequent accidents caused by human errors.

The blue mark indicates the area with no accidents caused by human error.

The example of navigation along the upper Mississippi river shows the estimated coefficients of hazard due to human error (Figure 2). According to publications (buergerimstaat.de), it is estimated that the Mississippi's locks, and curves are considered hazardous for navigation due to a possible human error. The similar situation relates to bridges due to their relatively low height.

In the areas close to obstacles, such as dams, junctions, bridges, shallow waters and channels the possibility of accident caused by human error is relatively high, and the relevant coefficients reach middle values (Vidan et al., 2012).

The areas with no hazards that have relatively low 
coefficients of hazard caused by human error are in the areas where navigation is unobstructed, traffic density is low or medium, depths are safe etc. (Vidan et al., 2012).

It is necessary to apply the adequate statistical processing of the valid data in real examples. In various countries such data are often unobtainable, as they are considered protected data related to crucial USA and/or national infrastructures.

\section{IMPLEMENTATION OF NEW MEASURES}

It is proposed to regard all information related to the safety of navigation along inland waterways as Inland Water Safety Information - IWSI. They should be distributed to the user by:

- Regular broadcasting of radio notices related to IWSI,

- Publishing them in river navigation charts,

- Publishing them in river navigational publications.

Regular broadcast of radio notices related to IWSI need to be classified as Search and Rescue-SAR, Meteo-MET and Navigational Warnings-NAVWAR and the national coordinator for each category need to be appointed (Vidan, et al, 2012). In order to follow the data on the safety of the waterway it is necessary to establish the Inland Water Information Service-IWIS for all critical areas. The data may be available by means of VHF (Very High Frequency) or MF (Medium Frequency) devices, NAVTEX, INMARSAT etc. It is also proposed to organise the global coordination service of such information - World Wide Inland Water Information Service WWIWIS (Kasum et al., 2010).

It is necessary to establish standards in the production of river navigation charts similar to Electronics Chart Display and Information System-ECDIS that are already in use in river navigation. In order to increase the navigation safety level it is necessary to expand their information content with, for instance, new proposed measures.

It is necessary to propose standards in the production of river navigational publications by integrating IWSI into their information content that otherwise would congest the content of river navigation charts.

It is also proposed to use the suggested approach in the development of new measures in order to establish international standards and their world-wide implementation.

\section{CONCLUSION}

Inland waterway traffic is considered to be the most costeffective form of land transportation. Development of safety on inland waterways was lagging behind the rate of traffic increase on them and largely lagging behind the development of safety in maritime transport. In order to increase the level of safety of navigation, new measures of safety and security of inland navigation waterways are proposed.
It is expected to reach an increase of safety and security by implementing new measures. It has been proposed to increase the safety and security of waterways by new marking in inland navigation charts. Possible human errors that occur as a result of collision avoidance manoeuvre on waterways can be reduced by new approach to labelling inland waterways in charts.

The use of inland waterways in global traffic is constantly increasing. The increase of traffic consequently increases the possibility of collision and of other undesired events. By increasing the navigational safety level it is possible to decrease consequential damages.

It is necessary to develop international standards relating to Inland Water Safety Information - IWSI and the like. In order to increase their accuracy, availability and reliability it is proposed to establish a global coordination service - World Wide Inland Water Information Service - WWIWIS. It is proposed to distribute IWSI to the users by regular broadcasting of radio notices, by publishing river navigation charts and navigational publications.

It is assumed that the implementation of the new measures proposed in this paper will significantly affect the increase of safety level of inland waterway navigation.

\section{REFERENCES}

Communication from the Commission on the Promotion of Inland Waterway Transport "NAIADES", Commision of the European Communities, (2006), Brussels, available at: http://ec.europa.eu/transport/iw/doc/2006_01_17_naiades_staff_ working_en.pdf, date: 11th November 2009

\section{Jolić, N., (2006) Luke i ITS, Fakultet prometnih znanosti, Zagreb, Croatia}

Kasum, J., Vidan P., Baljak K., (2006), Act About Safety Protection of Merchant Ships and Ports Open to International Traffic and its Implementation, ICTS, Ljubljana, Slovenia.

Kasum, J., Vidan,P., Baljak, K., (2010), Threats and New Protection Measures in Inland Navigation, Promet, 22(2), pp. 143-146.

International Maritime Organisation (IMO), (2009) IMO web page, available at: http://www.imo.org, date: 22nd December 2009

Inland Navigation Europe (INE), (2007), INE web page, available at: http://www. inlandnavigation.org/en/transport.html, [accesed 11 October 2009]

Port of Buenos Aires, (2008.), web page, available at: http://www.puertobuenosaires. gov.ar, [accessed 11 February 2012].

Vidan, P., Kasum, J., Zujić, M., (2009), Poboljšanje traganja i spašavanja na unutarnjim plovnim putovima, Naše More, 5-6 (56), p.187-192

Vidan, P., Kasum, J., (2012), Security of Hazmat Transports by Inland Waterways , Security Aspects of Uni-and Multimodal Hazmat Transportation Systems, Reniers L.L., Genserik ; Zamparini, Luca (ur.).Weinheim, Wiley-VCH, 2012, p. 71-89.

United States Coast Guard, available at: www.uscg.mil, [accessed 11 February 2012.].

DER BÜRGER IM STAAT: Der Rhein, available at: www.buergerimstaat.de/2_00/rhein. pdf, [accessed 27 March 2012.]. 